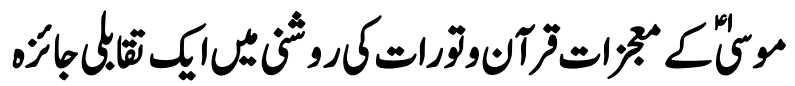

\section{The Miracles of Prophet Moses AS from the Perspective of Holy Quran and Torah: A Comparative Study}

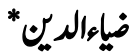 \\ مُ نمان
}

\begin{abstract}
Allah SWT; the Omnipotent, Almighty and Creator of the Universe, has created Human beings and Jins for His worship. He bestowed His revelation to His Prophets to guide creatures how to worship Him. Miracles are revealed to support their mission, which were considered manifestations of the prophethood and to nullify the doubts being raised regarding their message. The Holy Quran has testified the revelation of Torah but also verifies that it has been abrogated and manipulated by Jews and their scholars called Rabbis. The present study will undertake that how the Holy Quran and Torah describe the Divine intervention in the form of miracles; bestowed upon His prophet Moses AS, for the purpose to let the antagonists and unbelievers know that these prophets and their mission is true. It is found that there were decisive differences to approach the essence of miracles, presented in both religions; Islam and Judaism, which resulted discrimination in faith. To undertake this study, the researcher has adopted the comparative methodology of text reading and analysis of both Holy Quran and Torah.
\end{abstract}

Key Words: Moses, Miracles, Qur'an, Torah, abrogation and manipulation etc.
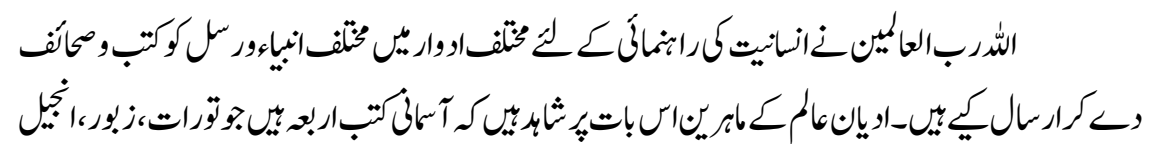

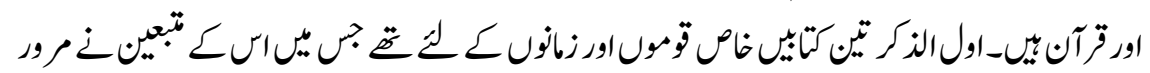

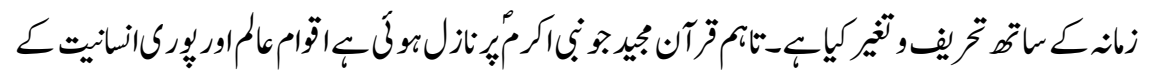

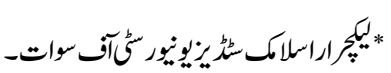

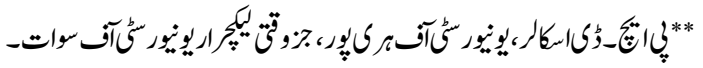




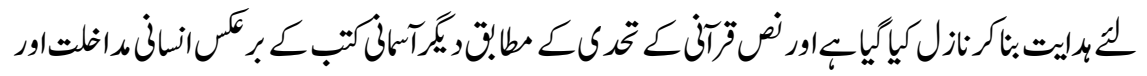

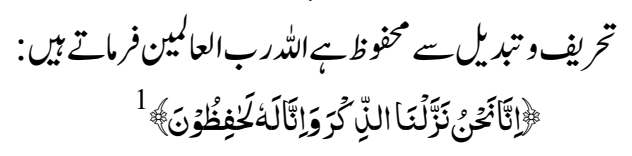

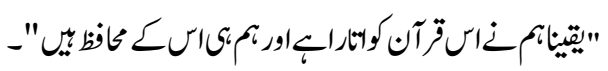

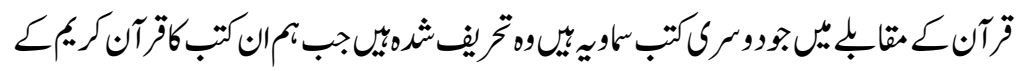

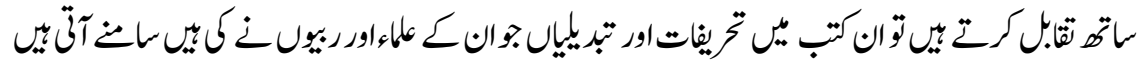

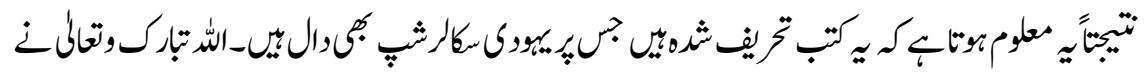

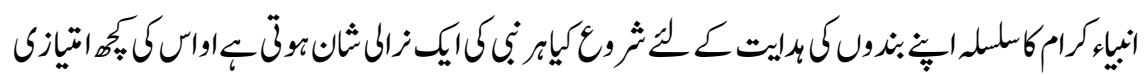

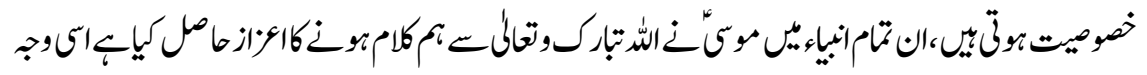

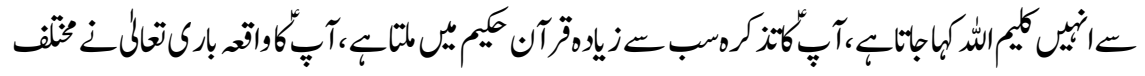

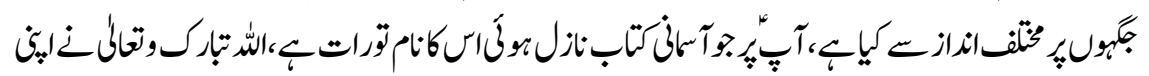

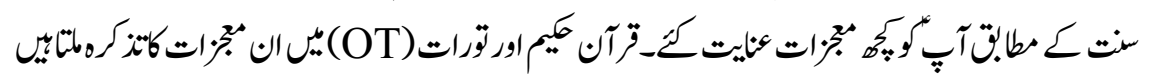

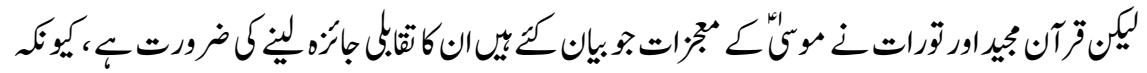

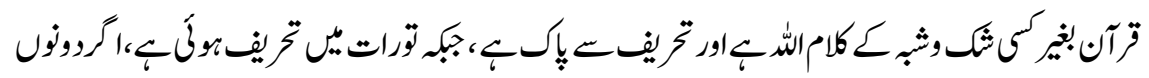

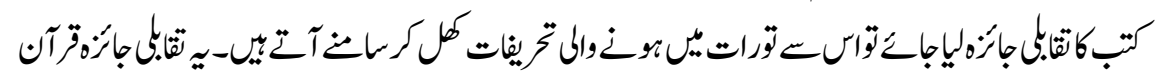

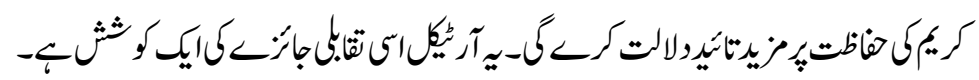

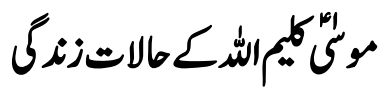

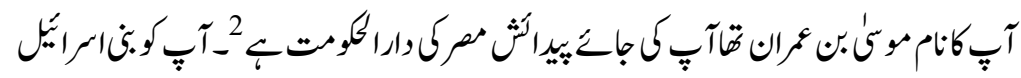

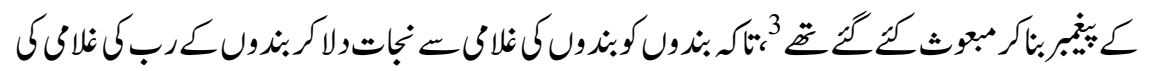

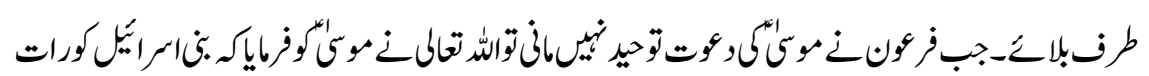

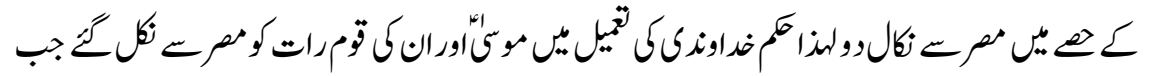

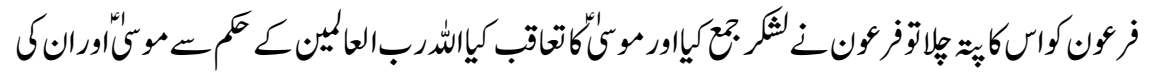

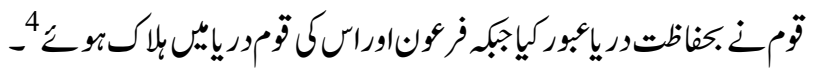




\section{موكى ميكمالشكمصفات}

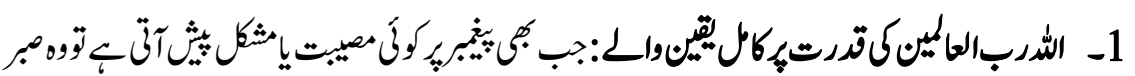

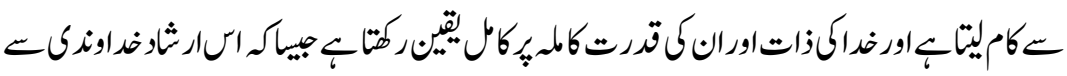

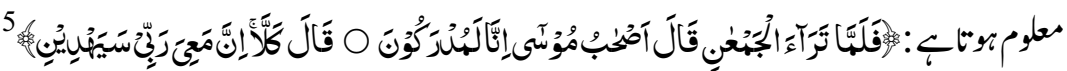

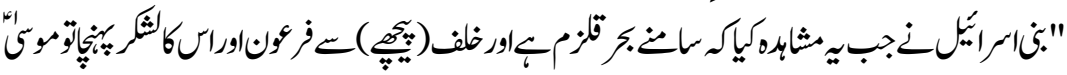

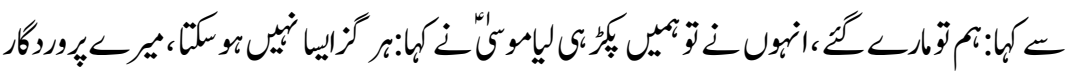

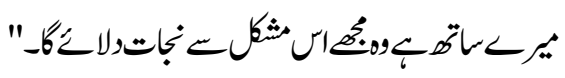

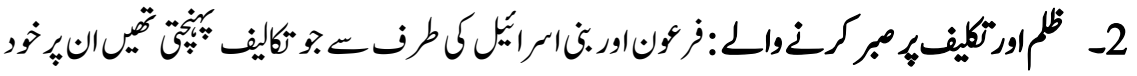

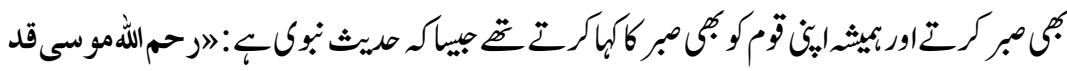

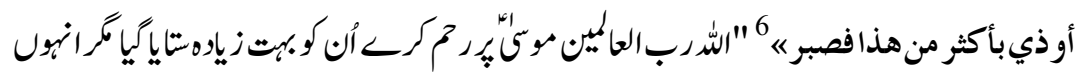

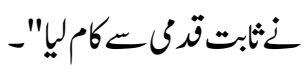

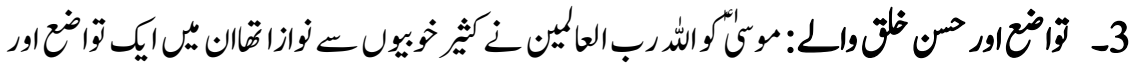

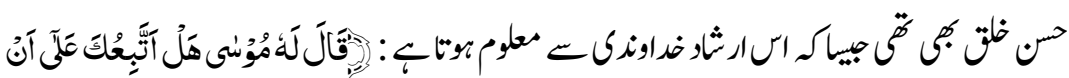

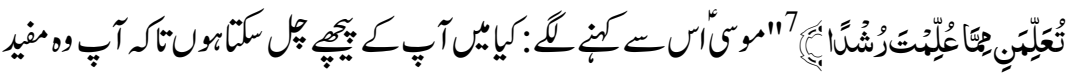

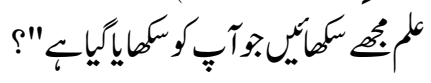

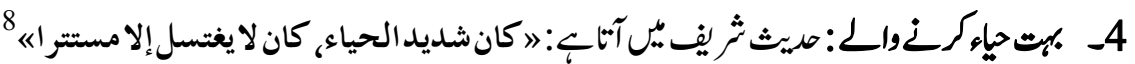

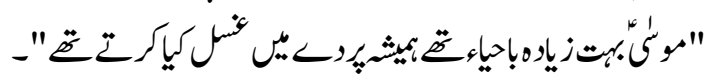

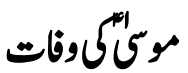

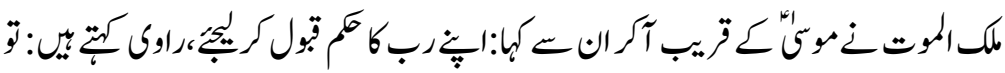

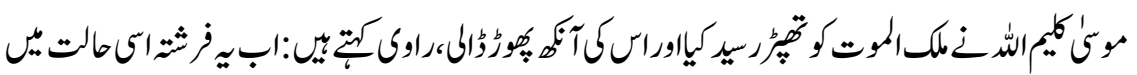

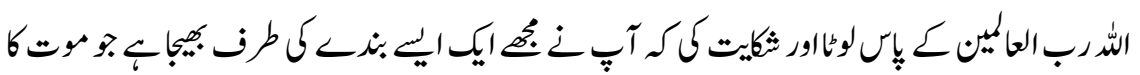

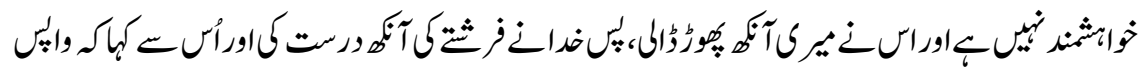

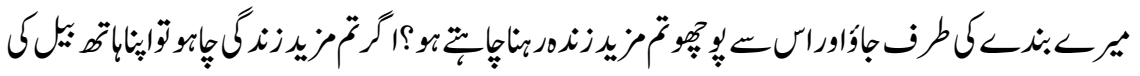




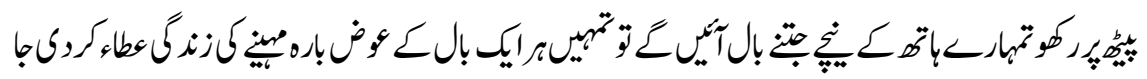

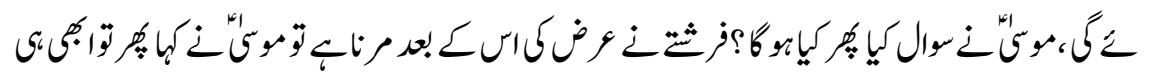
مير كروح تبن كرلو 9

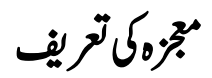

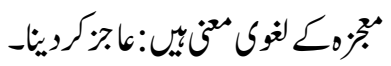

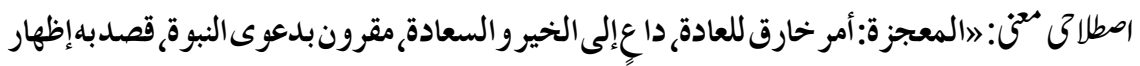

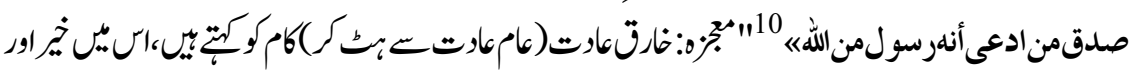

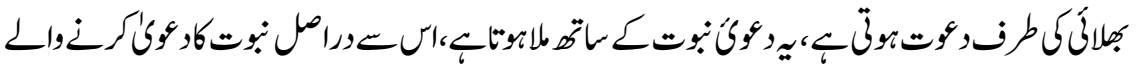

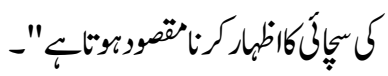

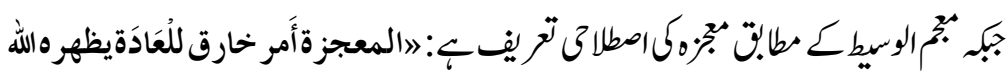

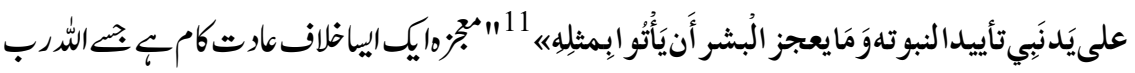

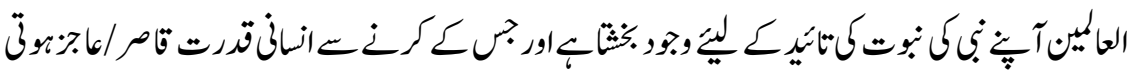

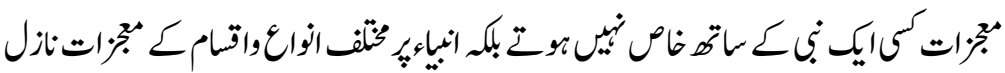
$"-6$

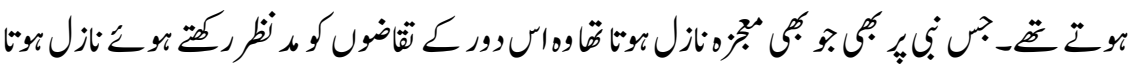

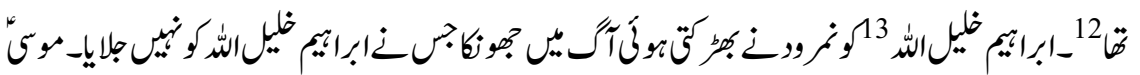

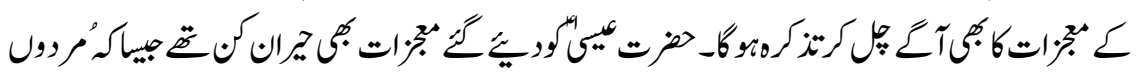

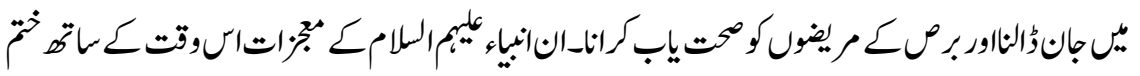

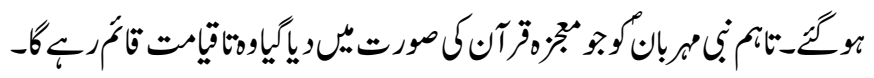

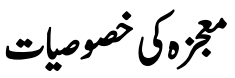

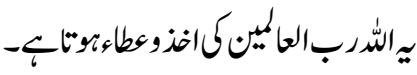

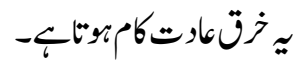

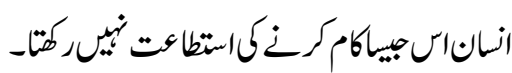




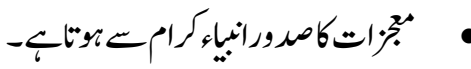

• • •

كرامتكمتر ليف

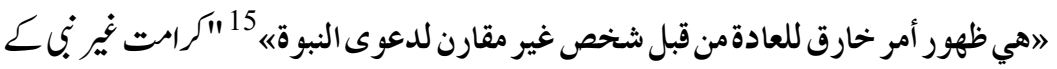

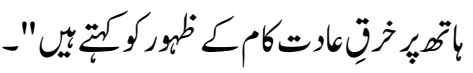

استدراتحكتخ ليف

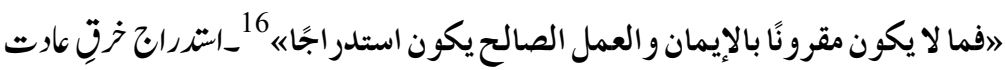

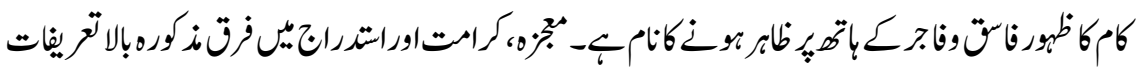
$-c$

\section{تورات(Torah)}

تورات

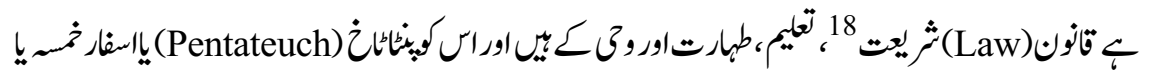

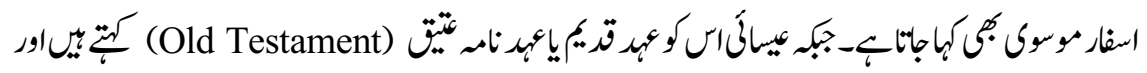

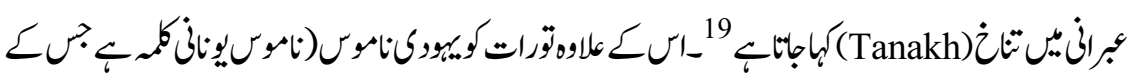

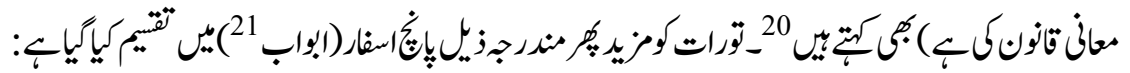

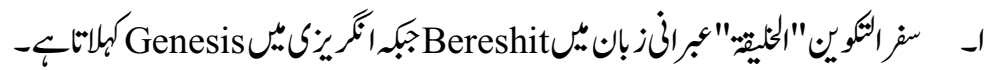

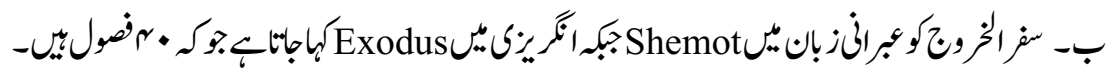

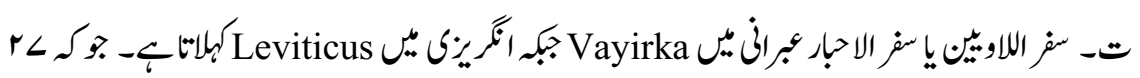
ضصوليث-

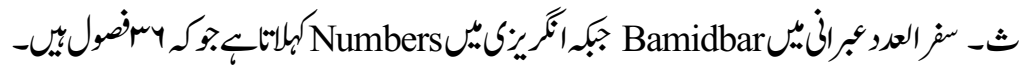

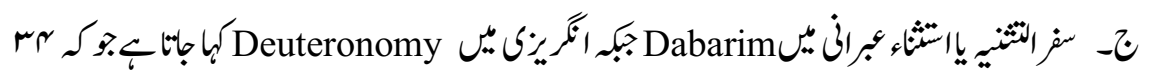
فصول:ب. 


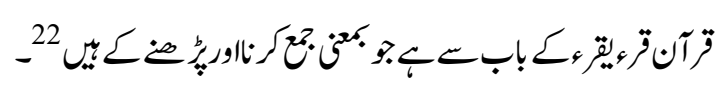

اصطلا حل تريف: هالقر آن: هو المنزل على الرسول المكتوب في المصاحف المنقول عنه نقلاً مثو اترًا بلا

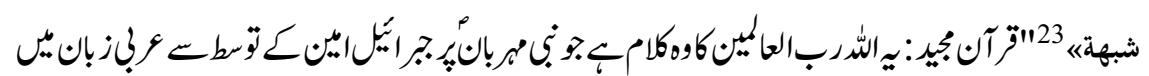

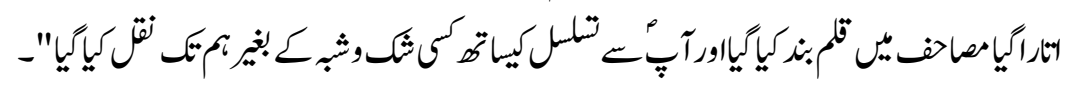

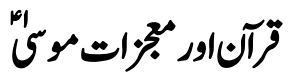

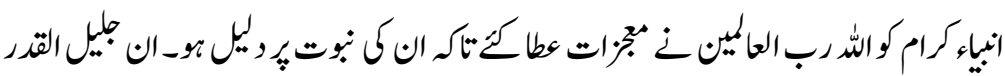

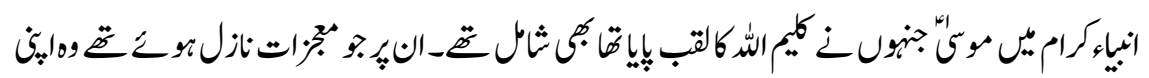

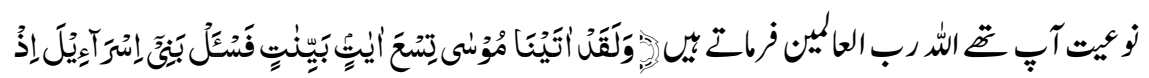

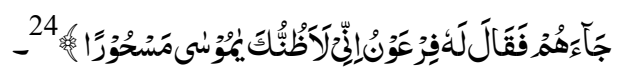

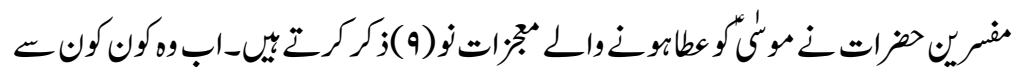

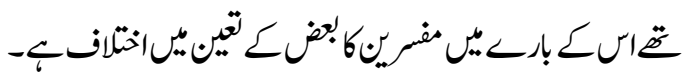

$$
\begin{aligned}
& \text { تمقنم مجّزات }
\end{aligned}
$$

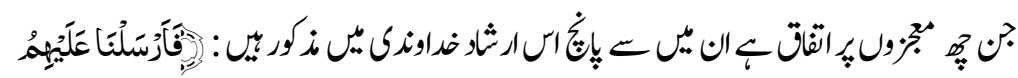

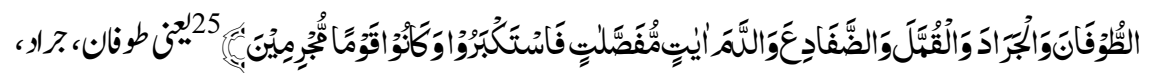

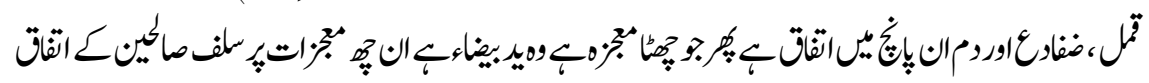

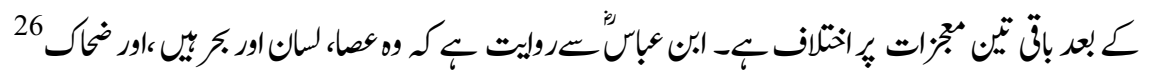

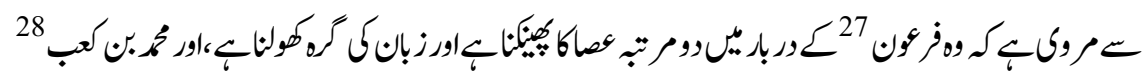

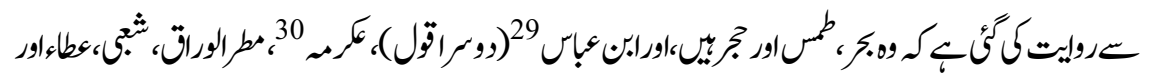

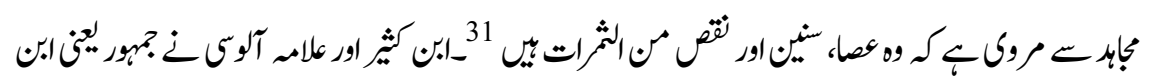

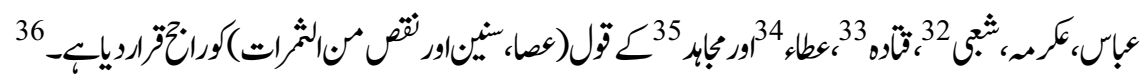




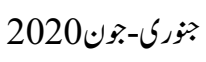

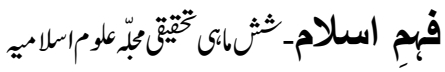

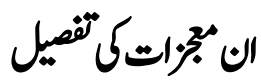

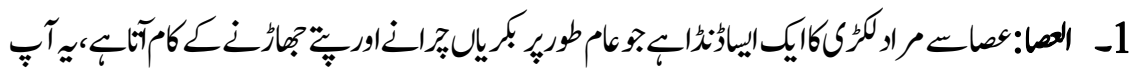

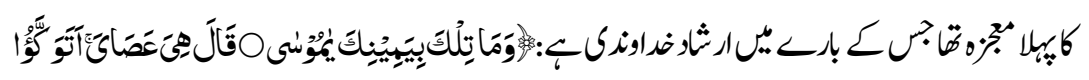

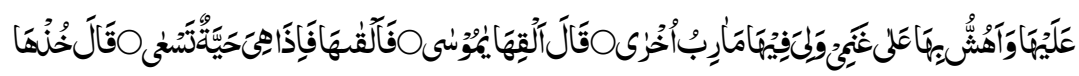

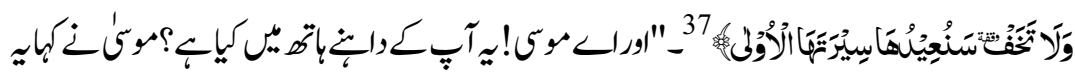

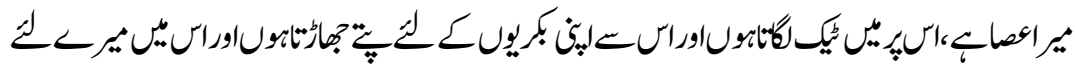

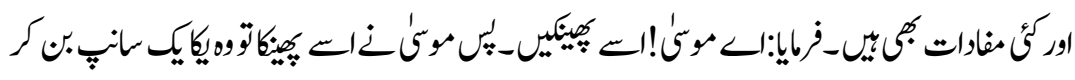

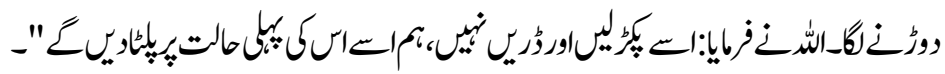

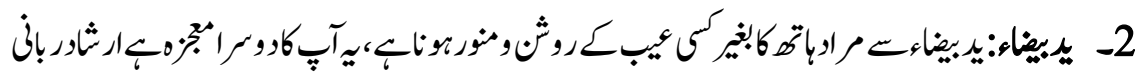

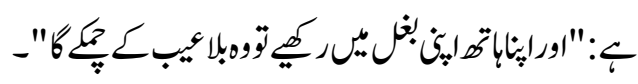

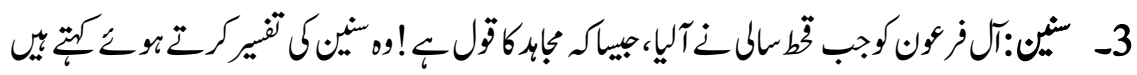
كم تشن-

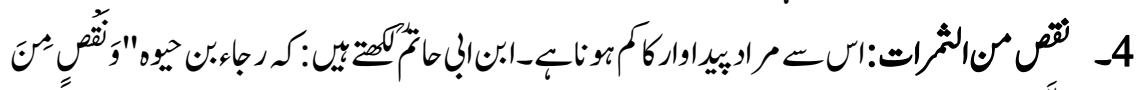

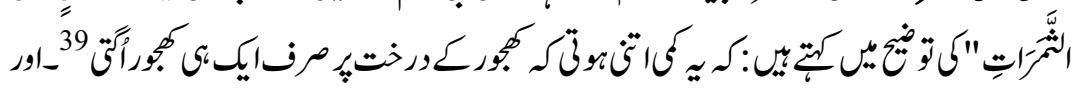

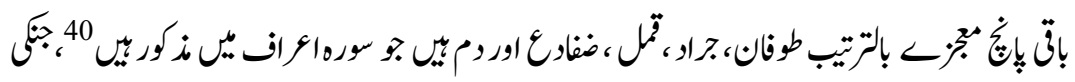

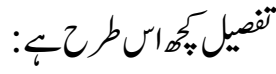

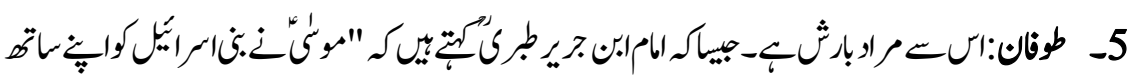

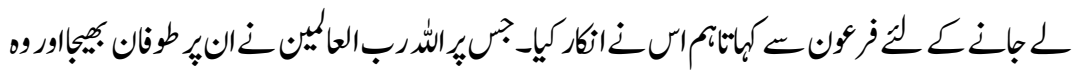

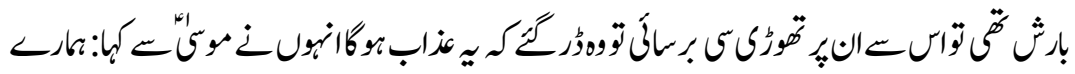

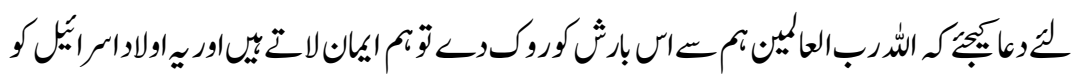

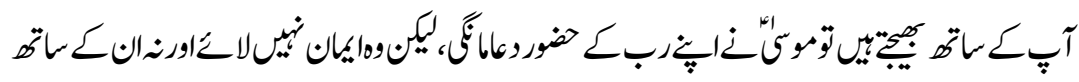

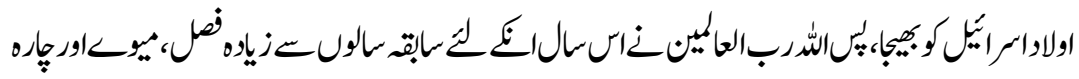

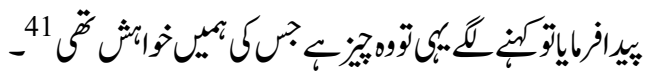

179 


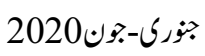

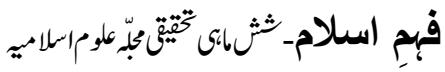

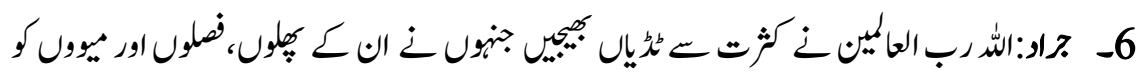

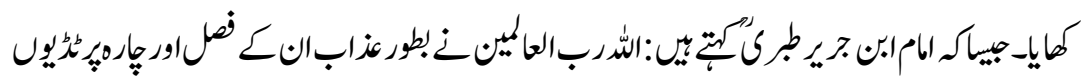

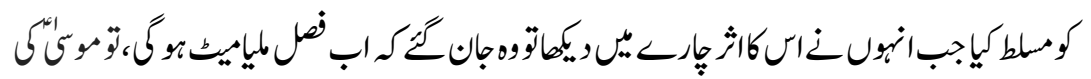

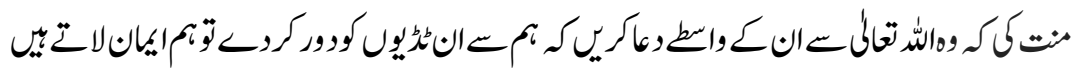

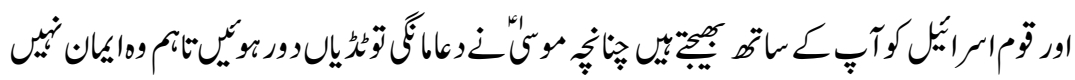

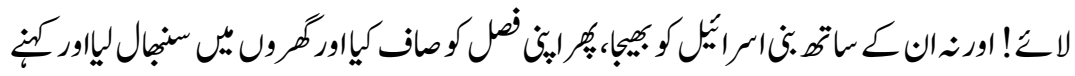

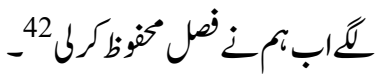

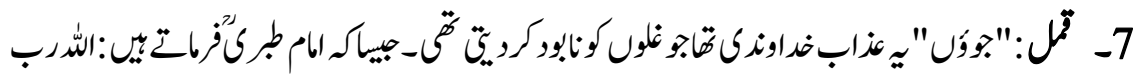

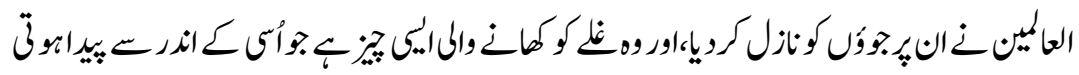

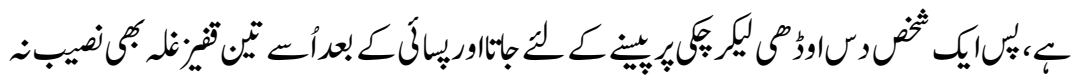

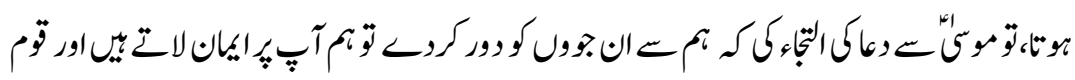

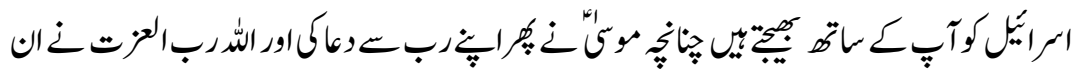

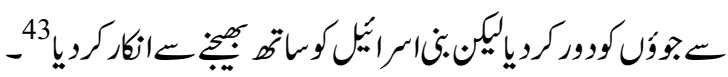

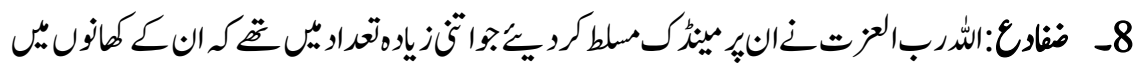

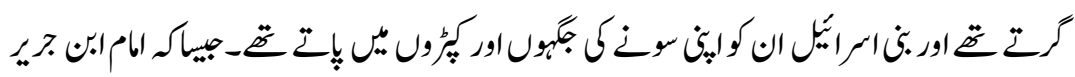

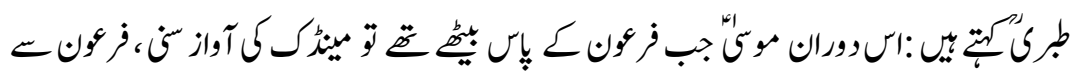

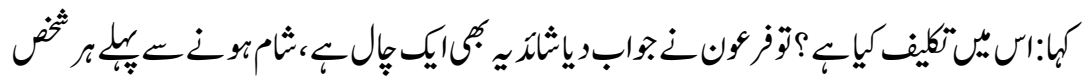

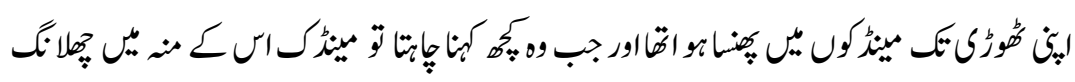

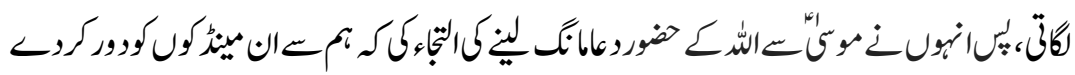

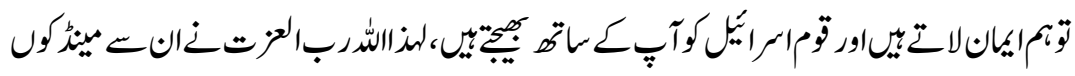

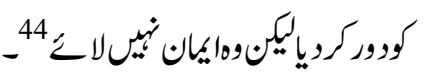

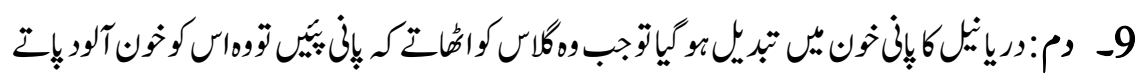

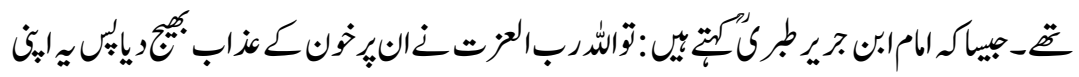

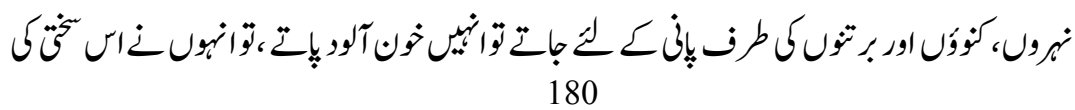




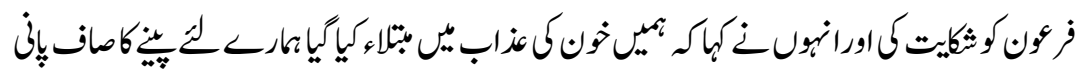

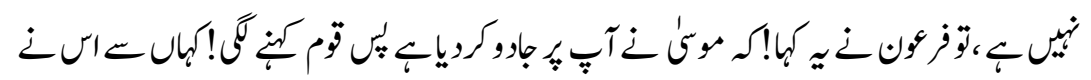

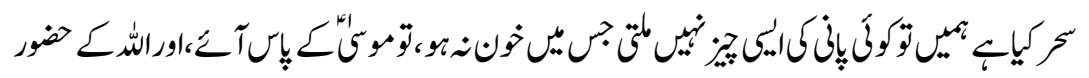

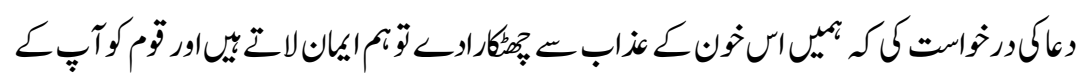

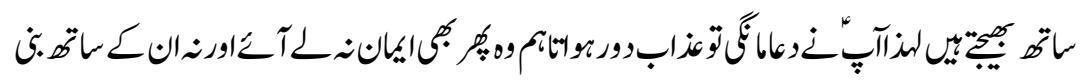

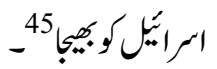

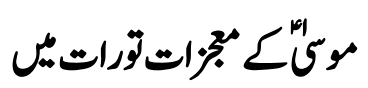

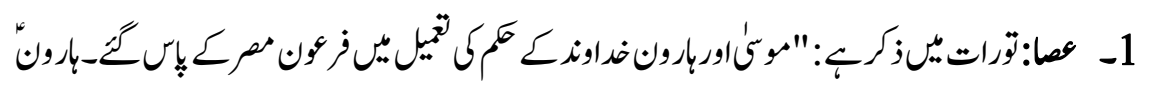

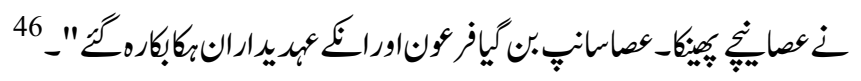

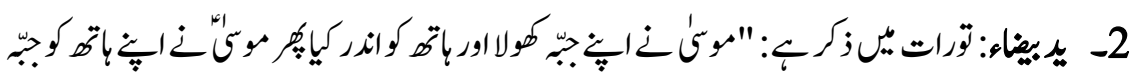

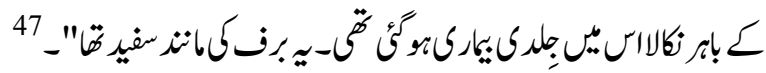

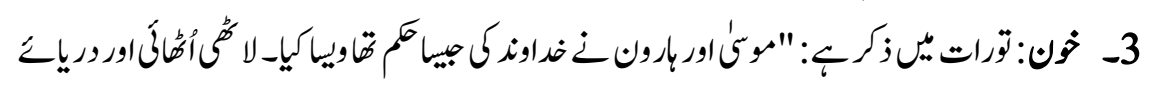

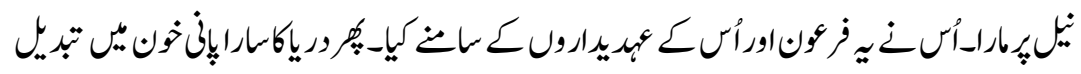

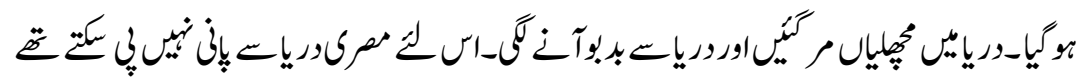

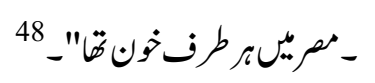

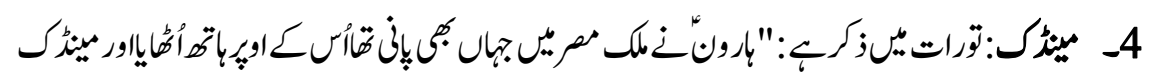

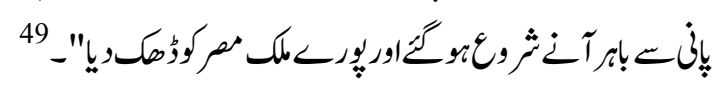

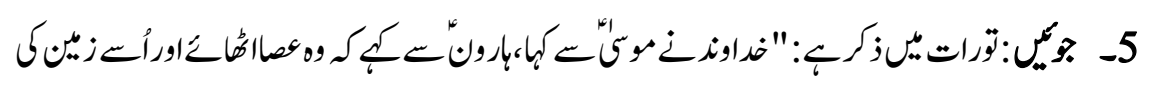

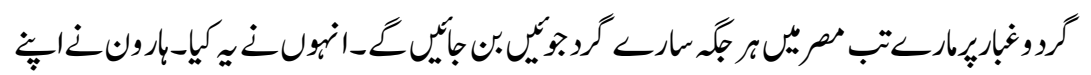

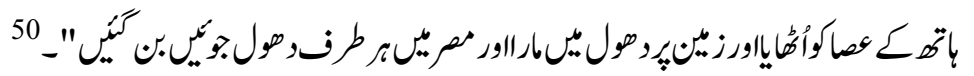

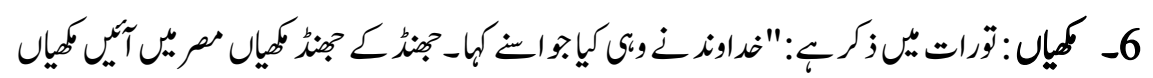

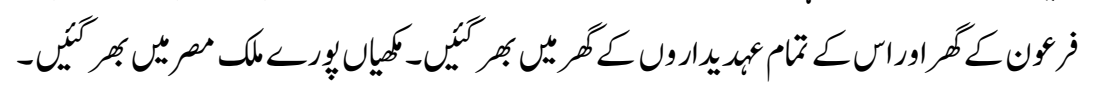

$$
\text { كمياس مكس كتباه كررنى تيّ" }
$$




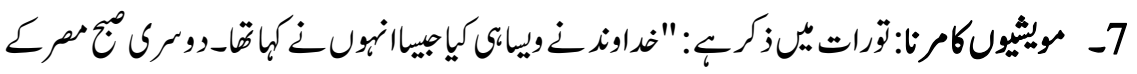

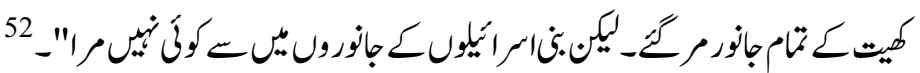

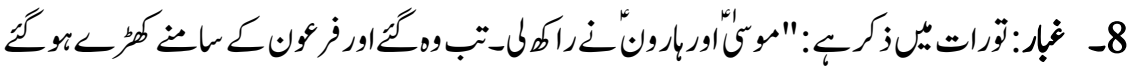

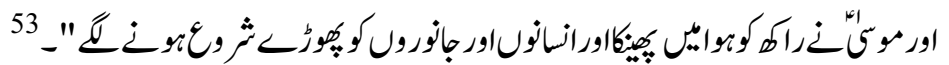

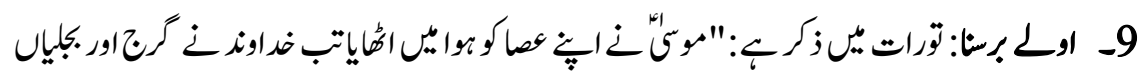

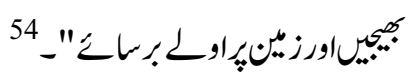

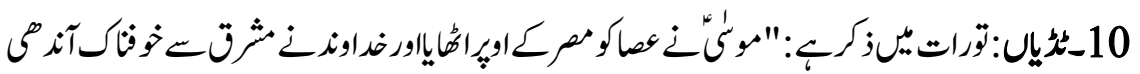

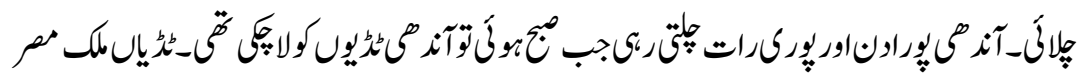

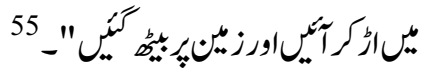

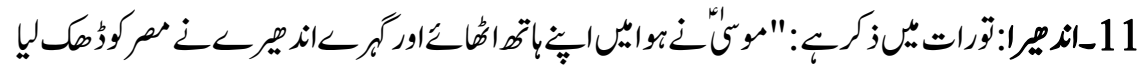

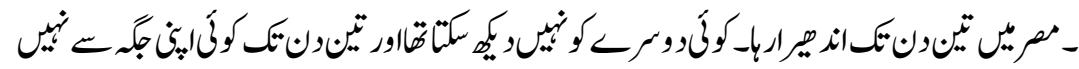

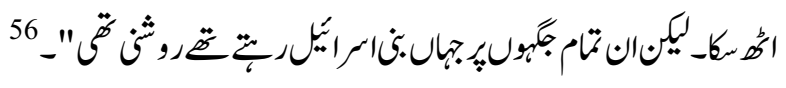

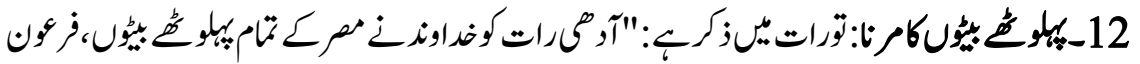

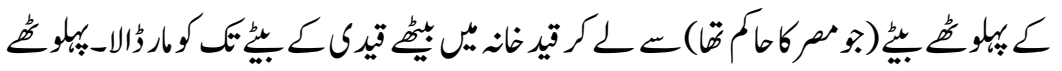

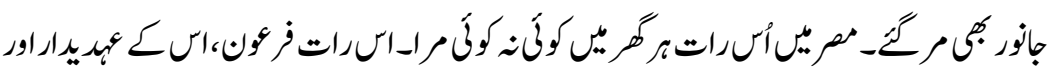

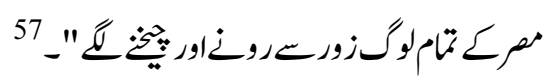

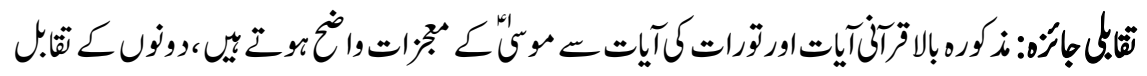

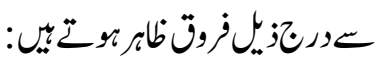

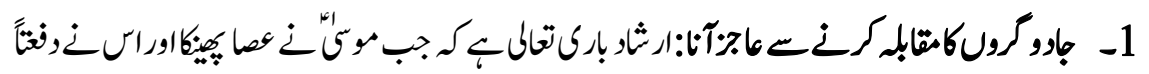

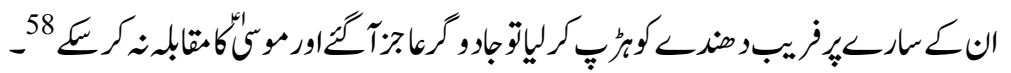

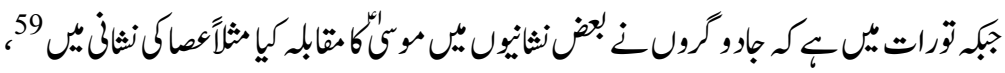

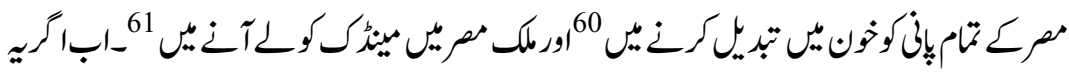

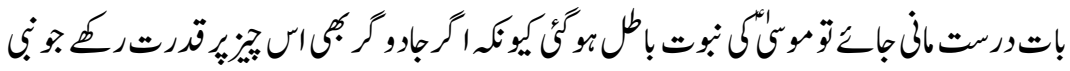




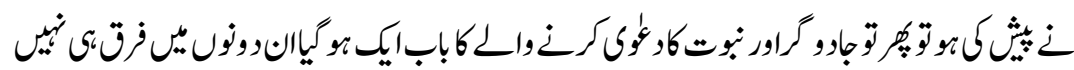

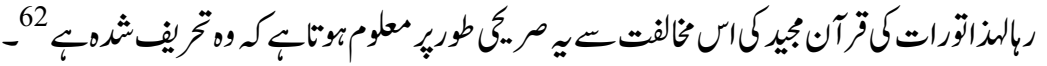

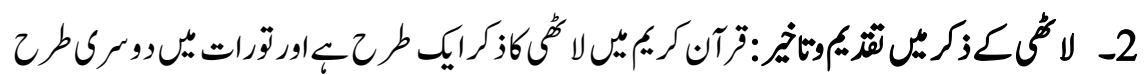

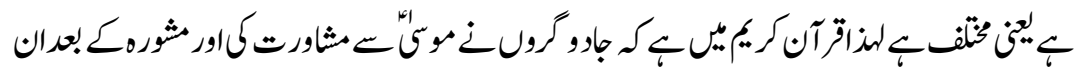

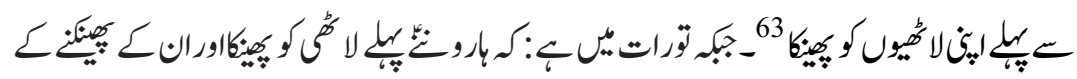

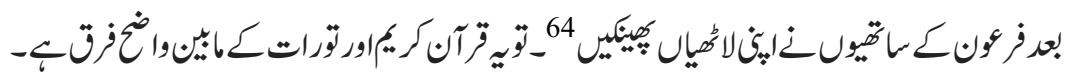

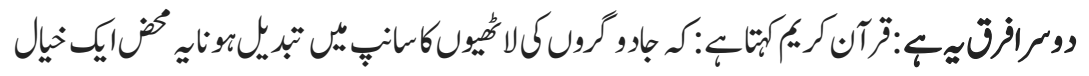

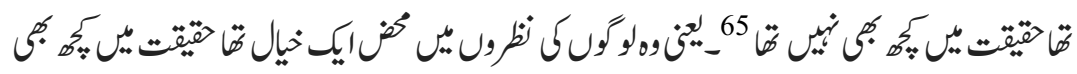

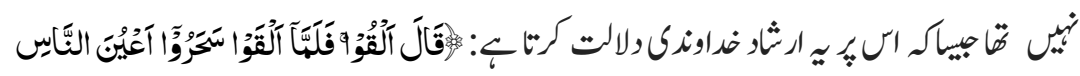

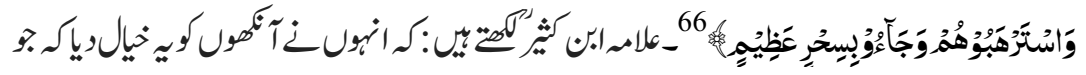

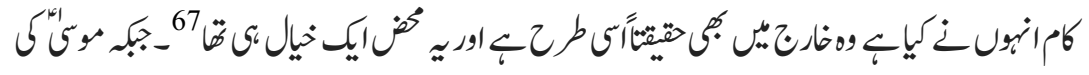

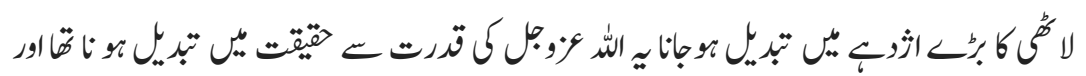

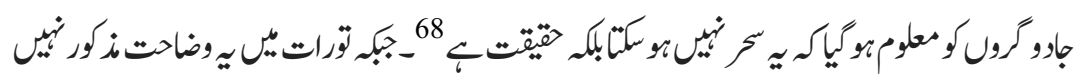

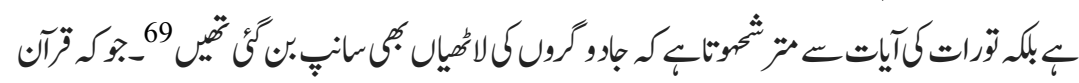

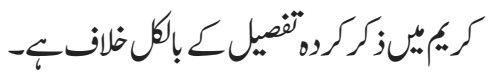

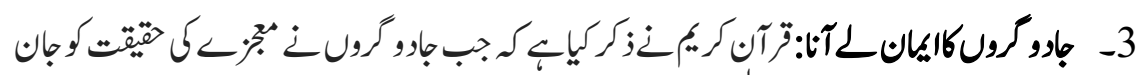

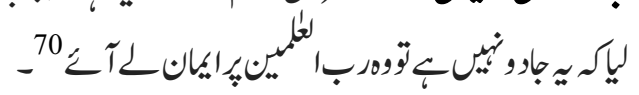

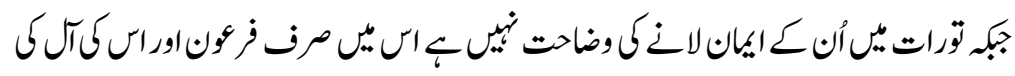

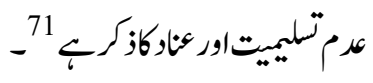

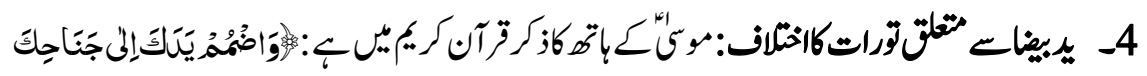

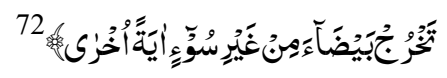

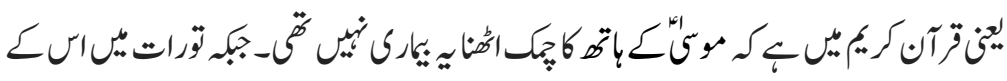

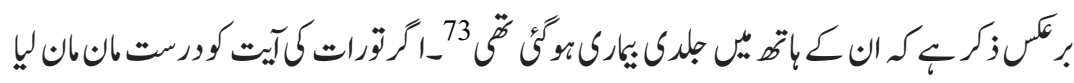

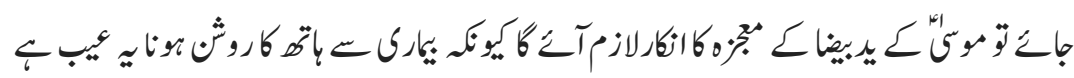




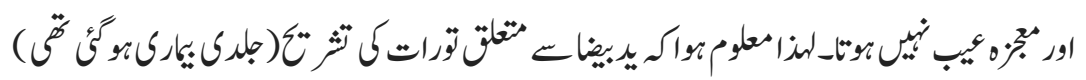

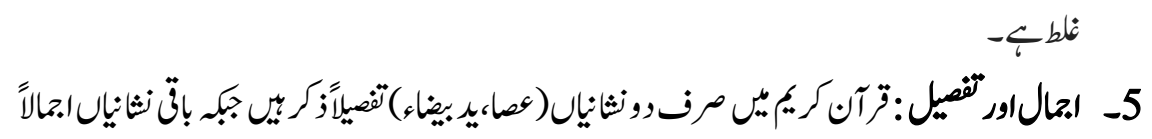

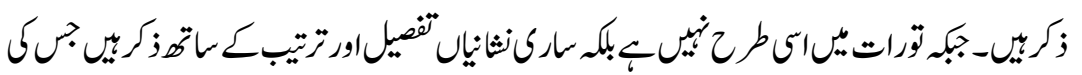

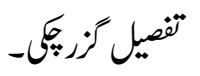

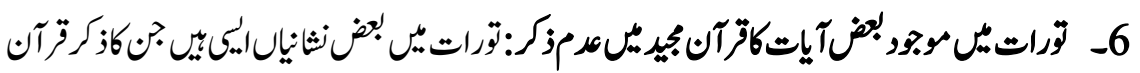

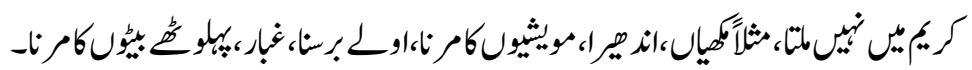

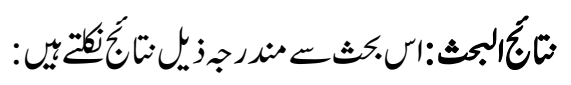

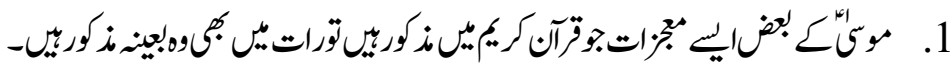

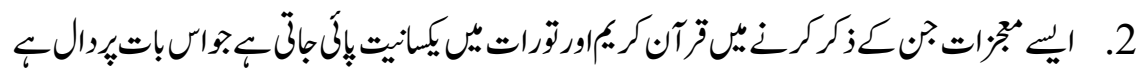

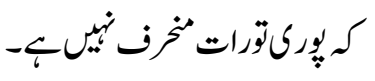

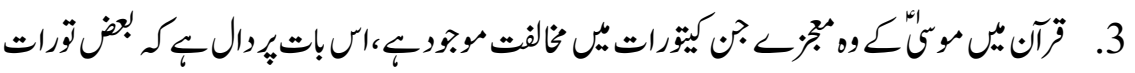

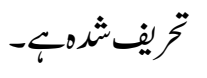

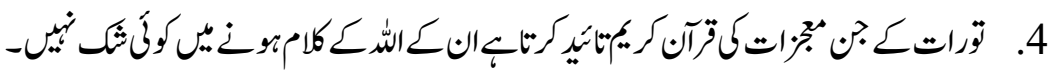

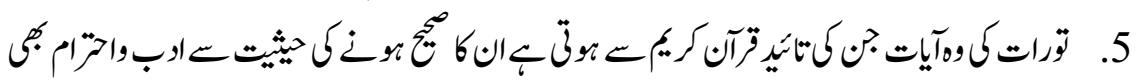

$$
\text { لازب }
$$

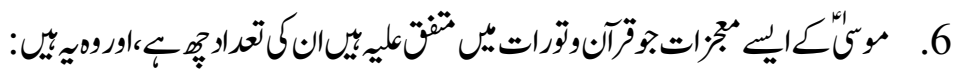

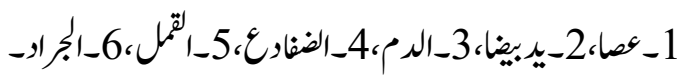

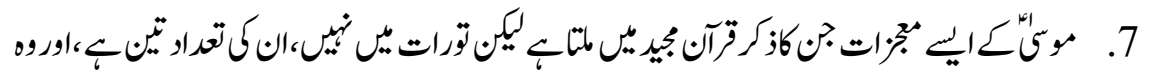

$$
\begin{aligned}
& \text { يثيّ: }
\end{aligned}
$$

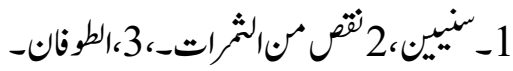

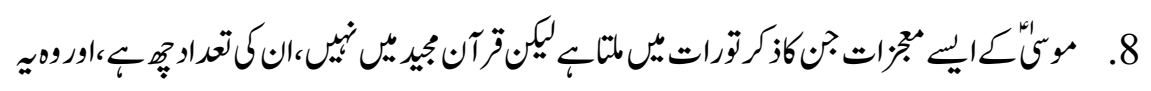

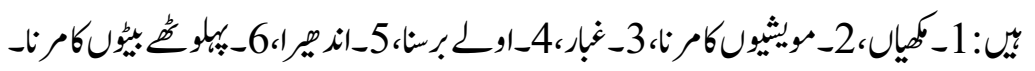




\section{(References ) والـ (ابت)}

$$
\begin{aligned}
& 1
\end{aligned}
$$

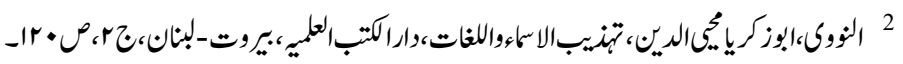

$$
\begin{aligned}
& 3 \\
& 4 \\
& 5
\end{aligned}
$$

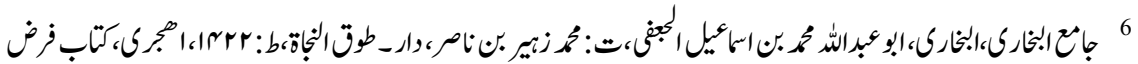

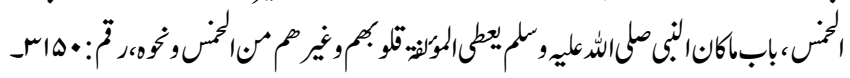

7

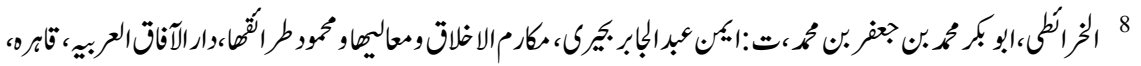

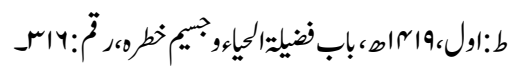

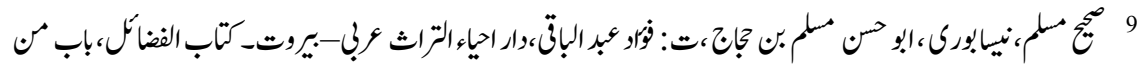

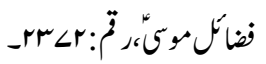

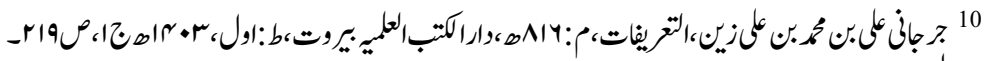

$$
11
$$

${ }^{12}$ The Concept of Revilation and Prophecy in Hinduism, A Critical

Islamic Review, M. Mudasir Ali, M.A Thesis, IIUII, 1999, PP 73- 75

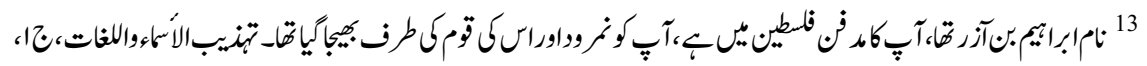

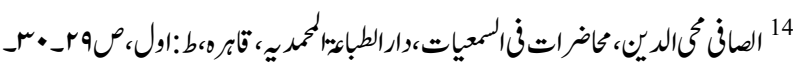

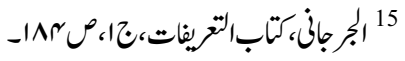

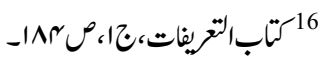

${ }^{17}$ Compiled somewhere around $538 \mathrm{BC}$, Torah is the result of long process of editing and thus no exact and precise date. Anyhow it was compiled between $5^{\text {th }}$ to $6^{\text {th }}$ centuries BC.

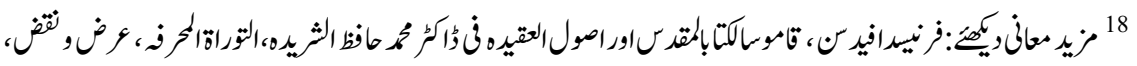




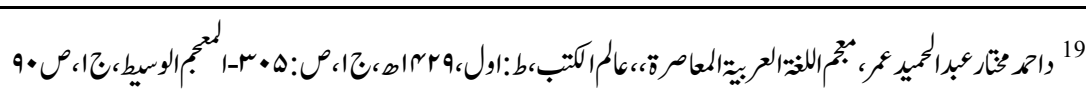

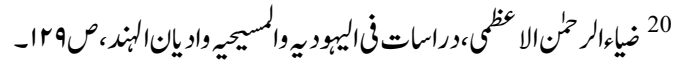

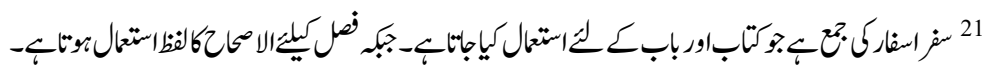

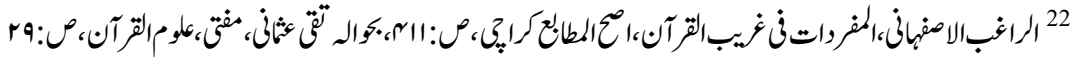

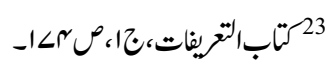
24

$$
25
$$

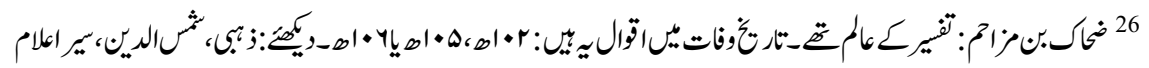

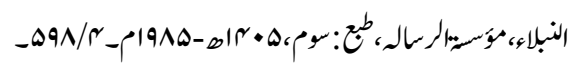

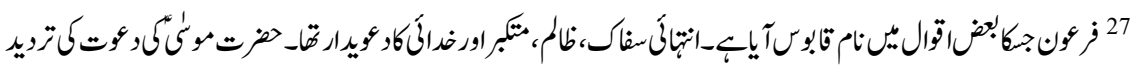

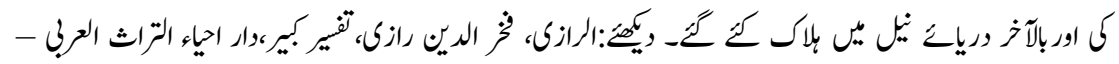

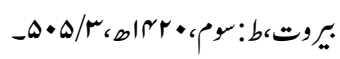

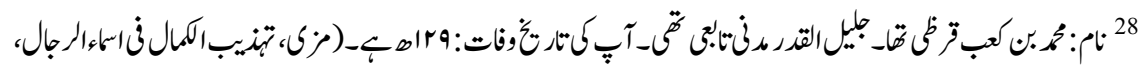

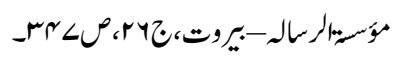

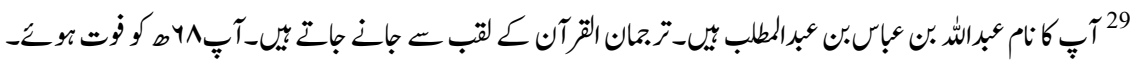

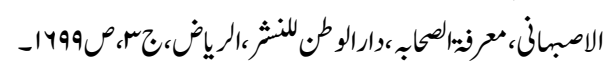

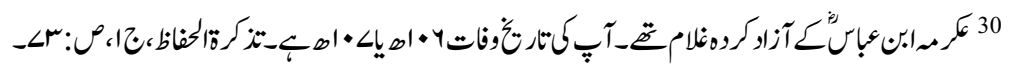

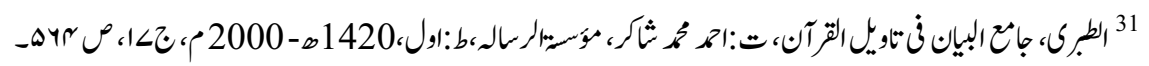

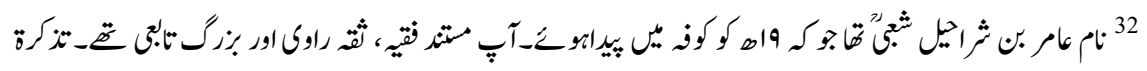

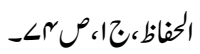

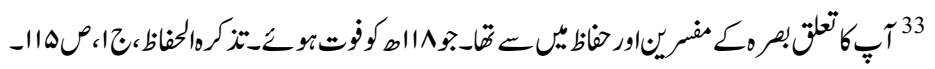
34

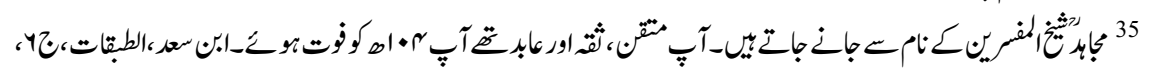
$-190$

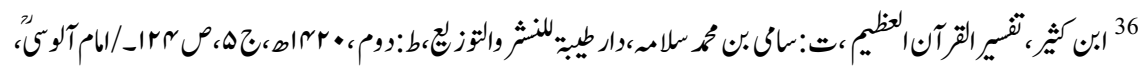

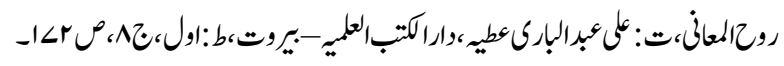




$$
37
$$

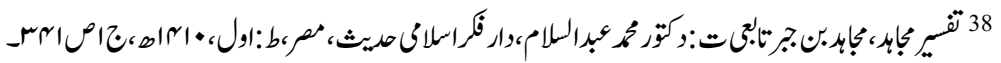

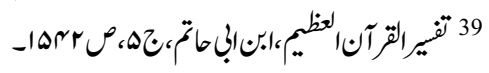

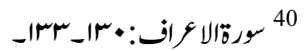

$$
\begin{aligned}
& 41 \text { تنير طبرك،تسا، } \\
& 42 \text { نغ المصدر- }
\end{aligned}
$$

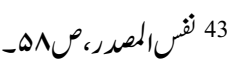

$$
\begin{aligned}
& 44 \\
& 45 \text { نونالمصدر- }
\end{aligned}
$$

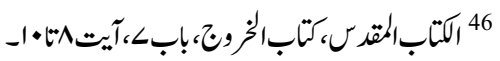

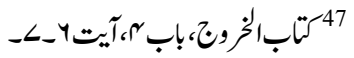

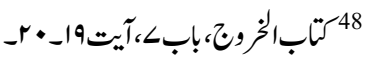

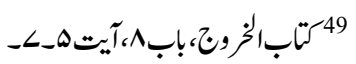

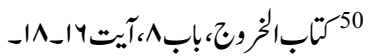$$
51
$$$$
52 \text { نُ المصرد،آيتا_ب- }
$$

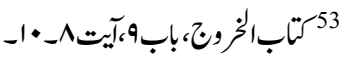

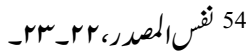

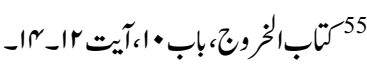

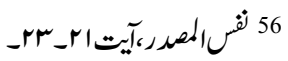

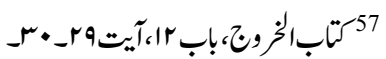

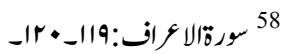

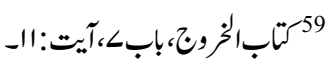$$
60 \text { نفرالمصرد،آيت:-r }
$$

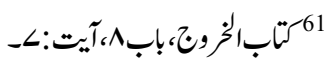$$
62 \text { سورةقالنساء:بry }
$$$$
63 \text { سورةالأواف:هه }
$$ 


$$
\begin{aligned}
& \text { 64كتاب الخروج،باب rاهآيت•1" } \\
& 65 \text { سورةط: } 64 \\
& 66 \text { بورة/الاؤاف:114 }
\end{aligned}
$$

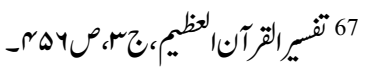

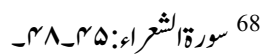

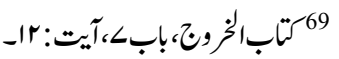

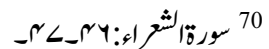

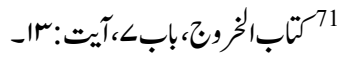

$$
\begin{aligned}
& 72
\end{aligned}
$$

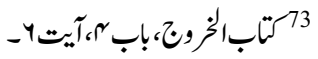

